\title{
RESPONSABILIDADE CIVIL DO CIRURGIÃO-DENTISTA
}

\author{
CIVIL LIABILITY OF DENTIST
}

\author{
Melissa Thiemi Kato* \\ Suzana Goya * \\ Sílvia Helena de Carvalho Sales Peres** \\ Arsenio Sales Peres **** \\ José Roberto de Magalhães Bastos ****
}

\section{RESUMO}

O estudo da responsabilidade civil referente às atividades do cirurgião-dentista mostra-se pertinente diante de um aumento peculiar do número de processos exigindo indenização do profissional, pelo erro. Será apresentado o estudo da responsabilidade civil do cirurgiáo-dentista por meio de revisão da literatura. Assim, tenta-se analisar as várias formas de incidência da responsabilidade civil na atividade do cirurgiâodentista, obtendo-se, por via reversa, condiçóes deste se prevenir para não ser responsabilizado, por meio de cuidados básicos.

DESCRITORES: Jurisprudência - Legislação Odontológica - Responsabilidade legal - Responsabilidade civil

\section{ABSTRACT}

The study of the civil liability of dentist's activities is opportune now due to a peculiar increase of the number of processes seeking this professional's compensation, by professional mistake. The study of the civil liability will be presented through revision of the literature. Therefore, it tries to analyze the several forms of incidence of the civil liability in the dentist activity, obtaining, for reverse road, conditions for him to prevent it for not become responsible and how take basic cares.

DESCRIPTORS: Jurisprudence - Legislation, dental - Liability, legal - Damage liability

* Mestrandas em Odontologia em Saúde Coletiva da Faculdade de Odontologia da Universidade de São Paulo (FOB/USP). E-mails: thiemikato@usp.br, suzagoya@usp.br

** Professora Assistente Doutora do Departamento de Odontopediatria, Ortodontia e Saúde Coletiva da Faculdade de Odontologia da Universidade de Sáo Paulo (FOB/USP). E-mail: shcperes@usp.br

*** Professor Doutor Responsável pela Disciplina de Deontologia, Legislação e Odontologia Legal do Departamento de Odontopediatria, Ortodontia e Odontologia em Saúde Coletiva da Faculdade de Odontologia da Universidade de São Paulo (FOB/USP). E-mail: arsenio@usp.br

**** Professor Doutor Títular e Coordenador da PG em Odontologia em Saúde Coletiva do Departamento de Odontopediatria, Ortodontia e Odontologia em Saúde Coletiva da Faculdade de Odontologia da Universidade de São Paulo (FOB/USP). E-mail: zeromaba@fob.usp.br 


\section{INTRODUÇÃO}

À medida que a sociedade evolui, a responsabilidade civil vai se tornando cada vez mais presente em nosso cotidiano (Kfouri Neto5, 2003). Está havendo, no Brasil, um aumento significativo de ações indenizatórias contra cirurgióes-dentistas, como ocorre em países do primeiro mundo, portanto, os dentistas estáo sujeitos a responder perante à Justiça a demandas fundadas na responsabilidade civil.

Assim, serão estudados os conceitos de responsabilidade civil contratual e extracontratual, bem como se sua atividade é considerada obrigação de meio ou de resultado (e as diferenças entre elas), além das excludentes de responsabilidade.

O paciente é considerado um consumidor de serviços, e por tal motivo, o cirurgião-dentista, como profissional liberal, responde também perante o direito do consumidor.

Por fim, vê-se a necessidade do cirurgião-dentista precaver-se das açóes cíveis por meio de documentação dos pacientes, que se traduz no prontuário odontológico, do qual será apresentado um modelo.

\section{REVISÃO DA LITERATURA}

\section{Responsabilidade civil contratual extracontratual}

Giostri $^{4}$ (2004) afirma que a responsabilidade no erro médico segue os mesmos ditames gerais da responsabilidade civil genérica. É obrigaçáo de quem, consciente e capaz, praticar uma conduta, de maneira livre, com intenção de fazê-lo e por simples culpa, ressarcir obrigatoriamente os prejuízos decorrentes do seu ato. Tal entendimento é extensível, por sua vez, ao cirurgião-dentista em decorrência de seu exercício profissional.

A responsabilidade está prevista tanto no Artigo 186 do Novo Código Civil ${ }^{3}$ (NCC), que dispóe sobre a responsabilidade civil extracontratual, quanto no artigo 951 do mesmo código, o qual estabelece a responsabilidade contratual.

“Art. 951. O disposto nos arts. 948, 949 e 950 aplicase ainda no caso de indenização devida por aquele que, no exercício de atividade profissional, por negligência, imprudência ou imperícia, causar a morte do paciente, agravar-lhe o mal, causar-lhe lesão, ou inabilitá-lo para o trabalho."

A imprudência consiste na prática de um ato perigoso, praticando por seu autor com descuido. Age com imprudência aquele que não age com moderaçáo, e não. Ele realiza uma conduta que a cautela indica que não deve ser realizada, ou seja, incorre em culpa. Essa imprudência facilmente se transforma em má prática quando leva o profissional a desprezar a dignidade do ser humano e a provocar-lhe danos graves (Nascimento ${ }^{8}, 2001$ ).

A negligência, por sua vez, é caracterizada pela ausência de precaução ou indiferença em relação ao ato realizado, revela-se na omissão de conduta que o profissional médico deveria adotar e não adota (Khouri' $\left.{ }^{6}, 1999\right)$. De um modo geral, a negligência é retratada por um comportamento omissivo. O agente deixa de fazer alguma coisa que a prudência impóe e, por seu descuido, ocorre o resultado danoso, ou seja, deixa de fazer um ato profilático.

A imperícia é a falta de aptidão ou habilidade técnica para o exercício de arte ou profissão, que, no caso, era exigível do autor, e se revela na deficiência de conhecimentos técnicos da profissão e despreparo prático, que exponham a riscos pacientes. No caso, o cirurgião-dentista, necessita de aptidão teórica e prática para o exercício de suas atividades. Portanto, o dano causado a outrem pelo agente, pela ausência de conhecimento técnico ou de prática de ato grosseiro no desempenho de suas atividades, decorre de imperícia (Kfouri Neto ${ }^{5}, 2003$ ).

$O$ Direito exige que esses profissionais exerçam a sua arte segundo os preceitos que ela estabelece, e com as cautelas e precauçõos necessárias ao resguardo da vida e da saúde dos clientes e fregueses, bens inestimáveis, que se lhes confiam no pressuposto de que zelem por eles. $\mathrm{E}$ esse dever de dominar a sua arte e aplicá-la, honesta e cuidadosamente, é tão imperioso, que a lei repressiva lhe pune as infraçóes, como comenta Beviláqua apud Kfouri $\operatorname{Neto}^{5}$ (2003).

A natureza da responsabilidade civil gerada no caso de erro profissional de cirurgião-dentista, geralmente é de natureza contratual. Segundo o Novo Código Civil ${ }^{3}$ (NCC) brasileiro, no ato em que o profissional aceita alguém como paciente estabelece-se entre as partes um contrato de trabalho (Gomes, Candelária e Silva, 1997 apud Kfouri Neto ${ }^{5}$, 2003), mesmo se este for de natureza verbal (contrato de locação de serviço). Tal fato ocorre quando o paciente procura pelo cirurgião-dentista, estabelecendo-se um consenso verbal de vontades em se aplicar um tratamento. Entretanto, excepcionalmente, tal responsabilidade pode ser de natureza extracontratual, e isso ocorre no caso de o profissional participar de um atendimento de emergência. Entretanto, a ocorrência de tal exceção é muito rara em Odontologia.

Prosseguindo no tema, o artigo 389 do $\mathrm{NCC}^{3}$ trata 
Kato MT, Goya S, Peres SHCS, Peres AS, Bastos JRM. Responsabilidade civil do cirurgião-dentista. Revista de Odontologia da Universidade Cidade de São Paulo 2008 jan-abr; 20(1):66-75

dos efeitos resultantes da responsabilidade civil oriunda dos contratos. Dispóe o Artigo 389:

"Art. 389. Não cumprida a obrigação, responde o devedor por perdas e danos, mais juros e atualização monetária segundo indices oficiais regularmente estabelecidos, e honorários de advogado."

Pela análise do artigo transcrito acima, pode-se observar que, na responsabilidade contratual, o dever de indenizar nasce do descumprimento de uma obrigação contratual prevista.

A diferença básica entre a responsabilidade contratual e a extracontratual, segundo o jurista Rodrigues ${ }^{10}$ (1993), é que "na hipótese de responsabilidade contratual, antes de a obrigação de indenizar emergir, existe, entre o inadimplente e seu co-contratante, um vínculo jurídico derivado da convençâo; na hipótese da responsabilidade extracontratual, nenhum liame jurídico existe entre o agente causador do dano e a vitima até que o ato daquele ponha em ação os princípios geradores de sua obrigação de indenizar".

Muitos autores entendem que não há motivos para disciplinar em separado as duas responsabilidades, por serem de igual natureza. Tal entendimento se deve ao fato de que ambas possuem vários pressupostos em comum. Tanto numa quanto ns outra são necessárias a existência do dano, da culpa do agente e a relaçáo de causalidade entre a conduta do agente e o dano sofrido pela vítima (responsabilidade extracontratual) ou pelo outro contratante (responsabilidade contratual). Outrossim, não se faz distinção entre a culpa contratual ou a extracontratual. Segundo Pereira" (2000) "Uma e outra apresentam pontos diferenciais no que diz respeito à matéria de prova e à extensão dos efeitos. São, porém, acidentais. Está presente a contravenção à norma, ou, como se exprime Pontes de Miranda: "A culpa é a mesma para infração contratual e para delitual" (loc cit) "Eventuais pontos de distinção referem-se a aspectos acidentais, relacionando-se à matéria de prova ou à extensão dos efeitos".

Todavia, diante do tratamento diferenciado dado pelo legislador pátrio, parece conveniente manter a distinção entre as responsabilidades contratual e extracontratual. E isso ocorre tanto no aspecto probatório como em relaçáo à extensão de seus efeitos. É possível estabelecer distinções em matéria de prova, quanto à fonte geradora da responsabilidade civil e quanto à capacidade das partes.

No campo probatório, tratando-se de responsabilidade contratual, cabe ao credor (contratante prejudicado), somente demonstrar o inadimplemento do devedor, ou seja, satisfazer a prova do não-cumprimento da obrigação gerada pelo contrato. Em contrapartida, ao devedor (contratante inadimplente) cabe provar a inexistência de culpa de sua parte, ou a presença de alguma excludente de responsabilidade com o fato de justificar o não-cumprimento da cláusula contratual por ele contraída: inexistência de culpa sua, caso fortuito ou de força maior.

Tratando-se de responsabilidade extracontratual, caberá à vítima o ônus de demonstrar a culpa do agente causador do dano, além da comprovação do dano e do nexo de causalidade (pressupostos exigíveis também da responsabilidade contratual).

Quanto à fonte geradora da responsabilidade civil, a contratual origina-se do acordo de vontades. É através do contrato que surgem as obrigaçóes contraídas que não serão cumpridas por um dos contratantes. A responsabilidade extracontratual tem sua fonte na lei, estabelecida basicamente no Artigo 186 do NCC $^{3}$ ("Aquele que, por ação ou omissãso voluntária, negligência ou por imprudência violar direito e causar dano a outrem, ainda que exclusivamente moral, comete ato ilícito").

Em matéria de capacidade, é importante saber a idade do causador do dano. Segundo o Artigo $4^{\circ}$ do NCC ${ }^{3}$, os maiores de 16 anos e menores de 18 anos sáo incapazes, relativamente a certos atos, ou à maneira de os exercer. E isto ocorre diante do fato de que na responsabilidade extracontratual, o menor púbere (entre 16 e 18 anos) responde sempre, como se capaz fosse (com o seu próprio patrimônio), pelos atos ilícitos em que for culpado. Por sua vez, na responsabilidade contratual, o menor relativamente incapaz somente se vincula se assistido por seu representante legal e, segundo Rodrigues ${ }^{10}$ (1993) "excepcionalmente sem ele, se maliciosamente declarou-se maior (NCC ${ }^{3}$, Art. 180); portanto, só pode ser responsabilizado por seu inadimplemento nesses casos".

\section{Obrigaçáo de meio e de resultado}

Em se tratando de responsabilidade civil de cirurgiãodentista, é necessário saber se o tratamento realizado é obrigação de meio ou de resultado.

Kfouri Neto $^{5}$ (2003), citando Demogue, afirma que "há obrigação de meio, quando a própria prestação nada mais exige do devedor que pura e simplesmente o emprego de determinado meio sem olhar o resultado. É o caso do médico, que se obriga a envidar seus melhores esforços e usar de todos os meios indispensáveis à obtençâo da cura do doente, mas sem jamais assegurar o resultado, ou seja, a própria cura". O profissional deve atuar com diligência, colocan- 
do à disposiçáo do paciente todo seu conhecimento. Se não obtiver êxito, não significa o descumprimento de sua obrigação contratual.

Por outro lado, na obrigação de resultado, o profissional (contratante), obriga-se a atingir determinado fim, desejado pelo paciente. O que interessa é o resultado final, não importando a diligência demonstrada durante o tratamento. Por conseguinte, se tal fim não for alcançado, não terá cumprido sua obrigação. Consegue o resultado ou deve arcar com as conseqüências. Sendo a obrigação de resultado, basta ao lesado demonstrar, além da existência do contrato, independente das suas razóes, cabendo ao devedor provar o caso fortuito ou de força maior, quando se exonerará da responsabilidade.

Stoco $^{13}$ (1999) assevera com relação aos cirurgiôesdentistas que: “... embora em alguns casos se possa dizer que a sua obrigação é de meio, na maioria das vezes apresenta-se como obrigação de resultado".

Menegale $^{7}$ (1997), com clareza, ensina que a obrigação decorrente do compromisso profissional de cirurgiãodentista é, em sua grande maioria, de resultados, porque “à patologia das infecçôes dentárias corresponde etiologia especifica e seus processos são mais regulares e restritos, sem embargo das relaçóes que podem determinar com desordens patológicas gerais; conseqüentemente, a sintomatologia, a diagnose e a terapêutica são muito mais definidas e é mais fácil para o profissional comprometer-se a curar".

Araújo $^{1}$ (1991) cita as especialidades que envolveriam obrigação de resultado: dentística restauradora, odontologia legal, odontologia preventiva e social, ortodontia, prótese dental e radiologia. Quanto à cirurgia e traumatologia buco-maxilo-facial, endodontia, periodontia, odontopediatria, ortodontia, patologia bucal e prótese buco-maxilo-facial, afirma que devem ser analisadas caso a caso (Kfouri Neto 5 , 2003).

\section{Excludentes da responsabilidade civil do cirur- giáo-dentista}

Segundo Simonetti ${ }^{12}$ (1999), são imprescindíveis as seguintes exigências legais para aferição da culpa do cirurgiáo-dentista; ausente um deles, descaracteriza-se a responsabilidade civil do profissional:

a) $O$ agente - cirurgião-dentista devidamente habilitado, caso contrário responderá por exercício ilegal da profissão, conforme Código Penal, Artigo 282.

b) $O$ ato - o dano deverá necessariamente advir de um ato profissional ilícito.

c) A culpa - consiste em proceder o agente sem a necessária cautela, deixando de empregar as precauçóes indicadas pela experiência como capazes de prevenir possíveis resultados lesivos.

d) $O$ dano - o resultado lesivo, por si só, não é o aspecto fundamental do crime culposo. Sua tipicidade reside em um determinado comportamento proibido pela norma. A açáo delituosa que a norma proíbe é a que se realiza com negligência, imprudência ou imperícia.

e) O nexo de causalidade - é o liame entre a ação ou omissão do cirurgião-dentista e o dano verificado no paciente, é a relação de causa e efeito. Se o paciente sofre o dano e, contudo, não fica provada a ligação com o comportamento do profissional, será improcedente a ação indenizatória.

\section{Código de defesa do consumidor}

O Código de Defesa do Consumidor ${ }^{2}$ traz, em seu Artigo $14, \$ 3^{\circ}$, o seguinte preceito:

"Art. 14....

$\int 4^{\circ} \mathrm{A}$ responsabilidade pessoal dos profissionais liberais será apurada mediante a verificação de culpa. "

Tal artigo recepciona o artigo 951, do $\mathrm{NCC}^{3}$, sendo extensível a todo prestador de serviços que atue como profissional liberal.

Novamente, é evidente que a culpa deverá ser demonstrada de forma clara e precisa, sem o que não poderá ser possível a responsabilização do profissional que exerceu o tratamento odontológico.

\section{DISCUSSÃO}

Vê-se a necessidade do cirurgiáo-dentista precaver-se das açóes cíveis por meio de documentação dos pacientes, de forma coerente e completa, que se traduz no prontuário odontológico. $\mathrm{O}$ prontuário é um conjunto de documentos padronizados, organizados e concisos que são destinados ao registro dos cuidados médicos e paramédicos prestados ao paciente, para uma correta avaliação do paciente, diagnóstico do caso, plano de tratamento, atendimento efetuado e proservação do paciente. Deve conter dois odontogramas, um inicial e outro final (para o término do tratamento); identificação do cirurgiãodentista com seu nome completo e número do Conselho Regional de Odontologia (CRO), identificação da ficha (contém a anamnese, proservação, previsão de honorários), identificação do paciente (nome completo, data de nascimento, gênero, estado civil, documento de identidade, cadastro de pessoa física (CPF), cor dos dentes, número das moldeiras, indicação, endereço com telefo- 
ne). No prontuário arquivam-se, também, radiografias e fotos, cópias de receitas assinadas pelo paciente, cópias dos atestados, cópias dos modelos de estudos, cópias dos recibos emitidos por folhas de receituários. A anamnese deve conter: identificação, queixa principal, história da doença atual, história médica pregressiva - inventário de saúde, antecedentes familiares, hábitos (higiene bucal e nocivos), história odontoestomatológica, espaço para exame clínico bucal (tecidos moles e duros), diagnóstico diferencial, diagnóstico final, prognóstico, exame físico extra-bucal: geral e loco-regional, exames complementares, prognóstico, planejamento terapêutico, intervençóes e proservação. Propóe-se, dessa forma, um modelo de prontuário odontológico (Anexos), complementado pelas informaçóes de Sales Peres et al. ${ }^{11}, 2001$.

\section{CONCLUSÃO}

Não resta dúvida de que, atualmente, os pacientes buscam cada vez mais a estética e a cosmética, ou seja, buscam a obrigação de resultado do cirurgiáo-dentista. Caberá a este procurar oferecer um contrato, visando à obrigação de meio, enfatizando a necessidade de saúde bucal ao paciente, ao invés de prometer resultados estético-cosméticos que venham a encher os olhos do paciente.
O paciente é considerado um consumidor de serviços, e por tal motivo, o cirurgiáo-dentista, como profissional liberal, responde também perante o direito do consumidor. As cautelas a serem tomadas pelo cirurgião-dentista são simples, mas sua repercussão é grande e eficaz: afastase, na maioria dos casos, a culpa. E, sem esta, não há que se falar em responsabilidade civil do cirurgiáo-dentista, pois tal responsabilidade é eminentemente subjetiva. Em outras palavras: se não demonstrada cabalmente a culpa, não há como imputar-se a responsabilidade ao cirurgiâodentista. Nesse caso, a incumbência será do devedor (cirurgião-dentista), que deverá afastar a presunção da culpa (em sentido amplo), comprovando-se que teve a conduta diligente e que, ainda assim, sobreveio o evento irresistível.

O prontuário deve ser uma rotina em todas as áreas da Odontologia para servir de auxílio na defesa do cirurgião-dentista diante de possíveis processos, bem como o relacionamento do profissional com o paciente deve ser a mais transparente e amigável possível.

\section{AGRADECIMENTOS}

Ao advogado César Lopes pela colaboraçãpo e a Rute Sant'Anna por ser exemplo de pessoa.

\section{REFERÊNCIAS}

1. Araújo ALM. In: Bittar, CA, Responsabilidade civil médica, odontológica e hospitalar. $1^{a}$ ed. São Paulo: Saraiva; 1991.

2. Brasil. Código de defesa do consumidor. São Paulo: Revista dos Tribunais; 1990.

3. Brasil. Senado Federal. Novo código civil: exposição de motivos e texto sancionado. Brasília: Subsecretaria de Edições Técnicas; 2003.

4. Giostri HT. Erro Médico à luz da jurisprudência Comentada. $2^{\mathrm{a}}$ ed. Curitiba: Juruá; 2004.

5. Kfouri Neto M. Responsabilidade civil do médico. $5^{a}$ ed. São Paulo: Revista dos Tribunais; 2003.

6. Khouri PR de, Erro médico. Brasília: Consulex; 1999.
7. Menegale G. Responsabilidade profissional do cirurgião-dentista. In: Dias, JA. Da responsabilidade civil, $3^{a}$ ed. Rio de Janeiro: Forense; 1997.

8. Nascimento AC. Responsabilidade civil médica. Maringá: Centro Universitário de Maringá; 2001. [Monografia]

9. Pereira CMS. Responsabilidade civil. $9^{a}$ ed. Rio de Janeiro: Forense; 2000.

10. Rodrigues S. Direito civil: responsabilidade civil. $13^{\mathrm{a}}$ ed. São Paulo: Saraiva; 1993.

11. Sales Peres A, Franco JB, Oltramari PVP, Albiero ALL, Sales Peres SHC. Prontuário odontológico: o meio mais adequado para o cirurgião dentista armazenar as informações dos seus pacientes. Revista de Odontologia da UNICID, 2001 set./dez; 13(3): 215220. 
12. Simonetti FAA. Responsabilidade civil do cirurgiãodentista. Rev. Ass. Paul. Cirurg. Dent. 1999; novdez; 53(6): 449-51.
13. Stoco, R. Responsabilidade civil e sua interpretação jurisprudencial. $4^{a}$ ed., São Paulo: Revista dos Tribunais, 1999.

Recebido em: 20/08/2005

Aceito em: 25/11/2006

DATA_______ N $\stackrel{0}{2}$ do prontuário:

\section{FICHA CLÍNICA}

Identifição do Paciente

Nome do paciente:

RG:

CPF ou CGC:

Endereço:

CEP:.

Bairro:

Cidade: UF:

Telefone residencial:

Telefone comercial: (.

...... Endereço Comercial: …...

CEP: Bairro:

Cidade: UF:

Gênero: Masculino ( ) Feminino ( )

Cor: Peso:

Data de Nascimento: Nacionalidade :

Idade: anos Estado Civil: 


\section{Apêndice B - Ficha Clínica}

$\mathrm{N}$ ํㅡㅇ do prontuário:

\section{ANAMNESE}

Está atualmente sob tratamento médico? $\quad \square$ afirmo $\quad \square \quad$ nego $\quad \square$ não sei

Qual o nome do médico e seu telefone?

Está tomando algum medicamento?

Qual?

Sofreu ou sofre alguma alteraçáo cardíaca? $\quad \square$ afirmo $\quad \square$ nego $\quad \square$ não sei

Pressão arterial: Máxima:

.. Mínima:

Controla periodicamente sua pressão? $\quad \square$ afirmo $\quad \square \quad$ nego $\quad \square$ não sei

È diabético? $\square$ afirmo $\quad \square$ nego $\quad \square$ não sei

Tem antecedentes familiares de diabetes? $\quad \square$ afirmo $\quad \square$ nego $\quad \square$ não sei

Tem tonturas ou desmaios com freqüência? $\quad \square$ afirmo $\quad \square \quad$ nego $\quad \square$ não sei

Tem ou teve aumento persistente de linfonodos? $\quad \square$ afirmo $\quad \square$ nego $\quad \square$ não sei

Tem algum tipo de alergia? $\square$ afirmo $\quad \square$ nego $\quad \square$ não sei

Qual?

Já tomou anestesia dentária? $\quad \square$ afirmo $\quad \square \quad$ nego $\quad \square$ não sei

Já tomou penicilina? $\square$ afirmo $\quad \square \quad$ nego $\quad \square$ não sei

Ocorreu algum fenômeno alérgico a essa droga? $\quad \square$ afirmo $\quad \square \quad$ nego $\quad \square$ não sei

Tem ou teve úlceras bucais repetidas vezes? $\quad \square$ afirmo $\quad \square \quad$ nego $\quad \square$ não sei
É fumante?
$\square$ afirmo
nego
$\square$ não sei

Quantos cigarros por dia?

Você bebe bebidas alcoólicas com freqüência? $\square$ afirmo $\quad \square \quad$ nego $\quad \square$ não sei

E, socialmente? $\quad \square$ afirmo $\quad \square$ nego $\quad \square$ não sei

Tem epilepsia? $\square$ afirmo $\quad \square$ nego $\quad \square$ não sei

Tem osteoporose? $\square$ afirmo $\quad \square$ nego $\quad \square$ não sei

Tem hábitos parafuncionais (bruxismo, apertamento, etc)? $\quad \square$ afirmo $\quad \square$ nego $\quad \square$ não sei

Costuma sangrar muito quando se corta? $\quad \square$ afirmo $\quad \square \quad$ nego $\quad \square$ não sei

Teve algum acidente hemorrágico? $\quad \square$ afirmo $\quad \square \quad$ nego $\quad \square$ não sei

Declaro que o respondido acima é verdadeiro.

Cidade, de de

Assinatura do paciente ou responsável 
$\mathrm{N} \stackrel{0}{\text { do prontuário: }}$

Tem ou teve febre inexplicável com freqüência?

$\square$ afirmo $\quad \square$ nego $\quad \square$ náo sei

Tem ou teve febre reumática? $\quad \square$ afirmo

nego $\quad \square$ não sei

Já teve algum tipo de hepatite?

$\square$ afirmo

$\square \quad$ nego

$\square$ não sei

Já sofreu transfusão sangüínea?

$\square$ afirmo

$\square$ não sei

Já teve algum tipo de tumor?

$\square$ afirmo

$\square$ não sei

Qual?

Já sofreu rádio ou quimioterapia? $\quad \square$ afirmo $\quad \square \quad$ nego $\quad \square$ não sei

Quando?

É usuário de drogas injetáveis? $\quad \square$ afirmo $\quad \square \quad$ nego $\quad \square$ não sei

Faz tempo que realizou extrações dentárias? Como foi?

Responda sim (S) ou não (N)

Suas extraçóes foram:

espontâneas

feitas pelo dentista

traumáticas (demoradas)

houve perda dentária por acidente ( )

PARA MULHERES:

Já entrou em processo de menopausa?

Está orientada pelo ginecologista?

$\square$ afirmo

$\square \quad$ nego $\quad \square$ não sei

Toma hormônio? $\square$ afirmo

$\square$ afirmo

nego

$\square$ náo sei

Toma cálcio?

$\square$ afirmo

$\square$ nego

$\square$ não sei

Está grávida?

$\square$ afirmo

$\square \quad$ nego

$\square$ não sei

Existe algum dado important

$\square \quad$ nego

$\square$ não sei

te que queira relatar e que acredite ser relevante para o sucesso do tratamento futuro?

…...........

Declaro que o respondido acima é verdadeiro.

Cidade, de de

Assinatura do paciente ou responsável 
$\mathrm{N} \cong$ do prontuário:

\section{PREVISÃO DE HONORÁRIOS}

O tratamento dentário é executado de acordo com um planejamento detalhado, baseado em informaçóes clínicas (exame de boca, análise facial e outras), advindas de documentação radiográfica dos maxilares e arcos dentários. A decisão do que fazer será tomada com base científica, mas influenciada pela experiência do profissional (e sua formação). O cliente (identificado no Anexo I) e/ou contratante tem as seguintes opçóes de plano de tratamento:

\section{OPÇÓES:}

Plano A:

…..

Plano B:

Plano C: -.....

Outras opçóes:

As opções sugeridas pelo contratado não são as únicas e, possivelmente, haveria outras.

Estou devidamente orientado(a) pelo contratado sobre as opçóes acima citadas.

$\mathrm{Eu}$ , contratante, escolho a opção

e autorizo a realização do tratamento. Aceito as vantagens, desvantagens e limitaçóes, que foram descritas na opção escolhida.

Cidade, ........... de ............................. de ...........

$\square$ Pai $\square$ Mãe $\square$ Tutor $\square$ Paciente

R.G.:

C.P.F.: 


\section{Apêndice D - Recibo}

\section{RECIBO}

Recebi do Sr.(a)

a quantia de $\mathrm{R} \$$

..) referente ao pagamento da parcela de seu tratamento odontológico referente aos honorários profissionais.

O presente pagamento é realizado:

$\square$ em dinheiro.

$\square$ através do cheque de número , banco. , agência.................. e de emissão de ficando condicionada a quitação à sua compensaçâao bancária.

Cidade, de. de. 